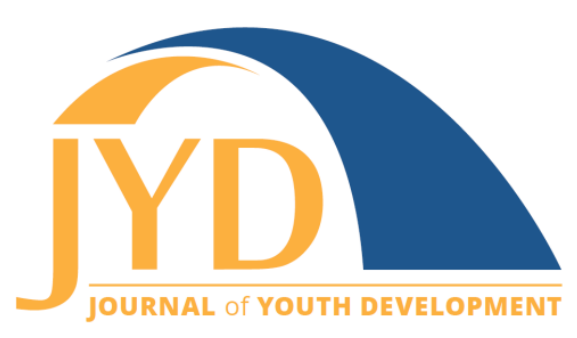

http://jyd.pitt.edu/ | Vol. 16 Issue 5 DOI 10.5195/jyd.2021.1189 | ISSN 2325-4017 (online)

\title{
Cultivating True Leaders: A Social Justice Curriculum for Youth Development Programs
}

\author{
Kamaria C. Massey \\ Morgan State University \\ kamas8@morgan.edu \\ Alexander E. Chan \\ University of Maryland Extension \\ alexchan@umd.edu \\ Edwin Green, Jr. \\ Stevenson University \\ egreen4@stevenson.edu

\section{Maru Gonzalez} \\ North Carolina State University \\ mgonza22@ncsu.edu
}

\begin{abstract}
In recent years, there have been increasing calls to intentionally center diversity, equity, and inclusion within positive youth development programs. True Leaders: Culture, Power and Justice is a 4-H curriculum designed to engage young people in understanding and applying social justice concepts with the ultimate aim of nurturing their sense of self-efficacy as they work to find solutions to pressing social issues. The True Leaders curriculum is shaped by the Five Cs of positive youth development-confidence, competence, connection, caring, and character-and a social justice youth development framework. Each lesson is grounded in the critical experiential learning model, which seeks to move participants through a process of hands-on learning about social justice concepts, critical reflection, and, ultimately, collective action. The True Leaders curriculum is intended for use with middle and high school-aged youth.
\end{abstract}

Key words: positive youth development, social justice youth development, 4-H, critical consciousness

\section{Introduction}

Exposing youth to experiences that are action-oriented, coupled with an intentional emphasis on recognizing, highlighting, and celebrating individuals' humanity can be the catalyst for

(cc) EY New articles in this journal are licensed under a Creative Commons Attribution 4.0 License. This journal is published by the University Library System, University of Pittsburgh and is cosponsored by the University of Pittsburgh Press. The Journal of Youth Development is the official peer-reviewed publication of the National Association of Extension 4-H Youth Development Professionals and the National AfterSchool Association. 


\section{Cultivating True Leaders}

effective social change (Gay, 2000; Hunjan \& Pettit, 2011). True Leaders: Culture, Power and Justice is a unique and necessary resource for youth development practitioners because it centers learning on the basic principle that all human beings are entitled to live a life free from any barriers that would hinder them from thriving.

Injustice in society demands calls for action. Programs that are developed using a social justice youth development (SJYD) framework, which centers critical consciousness development, can be the response to this demand. An SJYD framework establishes critical consciousness within youth by providing them with the knowledge and skills to challenge injustice and work toward collective action (Ginwright \& Cammarota, 2002). Engaging in critical dialogue concerning concepts and issues deemed taboo positively impacts human relationships and produces more inclusive societal norms.

\section{Curriculum Description}

\section{Background}

The True Leaders: Culture, Power and Justice curriculum is designed to give youth the chance to be social agents for change by allowing them to explore different identities, communities, cultures, and the histories that have shaped society. The curriculum highlights five main principles:

1. Analyze power in social relationships.

2. Make identity central.

3. Promote systemic social change.

4. Encourage collective action.

5. Embrace youth culture.

The facilitator will help students develop critical consciousness to enhance their awareness of oppressive structures in society (Heberle et al., 2020). Additionally, facilitators can expect to use the SJYD framework, rooted in culturally relevant pedagogy, to engage youth in constant reflection and active learning leading to community action. Facilitators should look forward to reflecting on their experiences, acknowledge inequity, challenge biases, and elevate youth voice (Fields et al., 2021).

\section{Format}

The lessons are intended to be used as independent lessons or as an entire curriculum. The curriculum is divided into five parts (Fields et al., 2021): 


\section{Cultivating True Leaders}

- Introduction and Context

- Cultural Identity

- Acknowledging and Appreciating Other Cultures

- Building Networks and Agency

- Power and Social Justice

The curriculum challenges youth and facilitators to engage in the activities that embrace cultural differences, power structures, and social justice. Each part has between four and six lessons that engage youth in hands-on activities. Students gain leadership and team-building skills that allow them to enact change in their communities.

The curriculum gives facilitators specific instructions that help them engage in ongoing reflection while guiding youth to complete action-based projects and activities that serve the community. The curriculum does this through the critical experiential learning process, an adaptation of the experiential learning model that is typical of 4-H curriculum: (a) experience an activity that is culturally relevant, (b) share observations, (c) process the experience or issue, generalize the experience in relation to social justice and equity, and (d) engage in collective action (Fields, 2017). This process aims to strengthen the Five Cs of youth development (competence, confidence, connection, character, and caring and compassion) to "increase the intentionality of inclusive language, with a focus on diversity, culturally relevance, and social justice" (Fields, 2017, Considerations section, para. 3).

\section{Considerations for Youth Development Professionals}

Working with youth on issues surrounding social justice will likely involve sharing personal histories of injustice. These histories may include stressors that could be categorized as adverse childhood experiences (ACEs; Anda et al., 2006). ACEs can include experiences such as abuse and neglect but may also include experiences of racism and discrimination (Wade et al., 2014). Some of these ACEs may be ongoing and not just in the past. Depending on their access to personal and environmental resources, youth may have varying abilities to cope with these stressors. During program implementation, adult staff should be watchful for signs of a developing emotional challenge (e.g., disengagement, panic, new anxieties, persistently low mood). As such, it would be advisable for adult staff to receive professional development in handling emotional issues through other programs, such as the Guide for Youth Development Professionals (z.umn.edu/YouthDevProfGuide). Preparing oneself in this way introduces relatively high demands on staff time before implementing the program. 


\section{Conclusion}

A social justice themed curriculum for 4-H is both timely and long overdue. The True Leaders curriculum provides facilitators with research-based lessons and supplemental resources that are easy to use and engage youth in gaining the critical understanding and self-efficacy necessary to participate in informed social change. Youth development professionals will benefit from the curriculum's emphasis on facilitator reflection and participant feedback.

\section{Ordering Information}

Title: True Leaders: Culture, Power and Justice

Contact information: hello@Shop4-H.org

Website: Shop 4-H (https://shop4-h.org/products/true-leaders-culture-power-and-justice)

Cost: $\$ 20.95$

\section{References}

Anda, R. F., Felitti, V. J., Bremner, J. D., Walker, J. D., Whitfield, C., Perry, B. D., Dube, S. R., \& Giles, W. $\mathrm{H}$. (2006). The enduring effects of abuse and related adverse experiences in childhood. European Archives of Psychiatry and Clinical Neuroscience, 256(3), 174-186.

(https://doi.org/10.1007/s00406-005-0624-4)

Fields, N. (2017). The contribution of urban 4-H to social capital and the implications for social justice. Journal of Extension, 55(6), Article 52. (https://tigerprints.clemson.edu/joe/vol55/iss6/52)

Fields, N., Chan, A., Gonzalez, M., Green, Jr., E., Moncloa, F., Massey, K., \& Nathaniel, K. (2021). True leaders: Culture, power and justice. $A$ youth development approach to social justice. National 4-H Council.

Gay, G. (2000). Culturally responsive teaching: Theory, research, and practice. Teachers College Press.

Ginwright, S., \& Cammarota, J. (2002). New terrain in youth development: The promise of a social justice approach. Social Justice, 29(4), 82-95.

Heberle, A. E., Rapa, L. J., \& Farago, F. (2020). Critical consciousness in children and adolescents: A systematic review, critical assessment, and recommendations for future research. Psychological Bulletin, 146(6), 525-551. (https://doi.org/10.1037/bul0000230) 
Journal of Youth Development | http://jyd.pitt.edu/ | Vol. 16 Issue 5 DOI 10.5195/jyd.2021.1189 Cultivating True Leaders

Hunjan, R., \& Pettit, J. (2011). Power: A practical quide for facilitating social change. Carnegie United Kingdom Trust. (https://www.carnegieuktrust.org.uk/publications/power-a-practical-guide-forfacilitating-social-change/)

Wade, R., Shea, J. A., Rubin, D., \& Wood, J. (2014). Adverse childhood experiences oflow-income urban youth. Pediatrics, 134(1), e13-e20. (https://doi.org/10.1542/peds.2013-2475) 